\title{
Parents' views on growth hormone treatment for their children: psychosocial issues
}

\author{
This article was published in the following Dove Press journal: \\ Patient Preference and Adherence \\ 24 July 2012 \\ Number of times this article has been viewed
}

\author{
Nadine van Dongen' \\ Ad A Kaptein ${ }^{2}$ \\ 'Patient Intelligence Panel Health \\ Ltd, London, United Kingdom; \\ ${ }^{2}$ Section Medical Psychology, Leiden \\ University Medical Centre, Leiden, \\ The Netherlands
}

Background: We evaluated the opinions of parents in The Netherlands concerning treatment of their children with growth hormone, and examined beliefs and perceptions about treatment and quality of health care communication and support.

Methods: An Internet survey was completed by 69 parents who had children prescribed growth hormone and were part of the Patient Intelligence Panel. Acceptance of the diagnosis and treatment was investigated with reference to four topics, ie, search and quality of information, involvement in decision-making process, operational aspects, and emotional problems and support.

Results: Among the parents surveyed, 48\% reported a lack of freedom to choose the type of growth hormone device that best suited their needs, $92 \%$ believed that their children (and they themselves) would benefit if the children self-administered growth hormone, and $65 \%$ believed training to support self-administration would be helpful. According to $79 \%$, the availability of support from another parent with experience of treating their own child with growth hormone, alongside their doctor, would be valuable. Thirty-seven percent of the parents indicated that their children felt anxious about administration of growth hormone, and $83 \%$ of parents would appreciate psychological support to overcome their anxiety. An increase in reluctance to receive treatment with growth hormone was observed by $40 \%$ of parents after the children reached puberty, and $57 \%$ of these parents would appreciate psychological support to overcome this reluctance.

Conclusion: Understanding how growth hormone treatments and their implications are perceived by parents is a first step towards addressing quality of growth hormone treatment, which may be instrumental in improving adherence. The data show a need for support and involvement of parents in the process of choosing a growth hormone device. This decision-making process may be instrumental in improving acceptance and diminishing emotional problems for children using growth hormone.

Keywords: growth hormone, parents, treatment beliefs, adherence, pediatric chronic disease

\section{Introduction}

Growth hormone, also called somatropin, is a polypeptide hormone produced and secreted by the anterior pituitary gland. It stimulates growth, cell reproduction, and cell regeneration. In children, the most important reason for treatment with growth hormone is impaired growth velocity caused by either insufficient growth hormone production, ie, growth hormone deficiency, or by an impaired response to physiological growth hormone levels, eg, Turner syndrome. Severe growth hormone deficiency in early childhood can have serious effects on muscle development, which can in turn be seen in delays in reaching milestones, such as standing, walking, and achieving body length. ${ }^{1}$
Correspondence: Nadine van Dongen PIP Health Ltd, 77 Bastwick Street, London ECIV 3PZ, United Kingdom Email nadine@piphealth.com 
In The Netherlands, around 2000 children presently receive daily growth hormone therapy. ${ }^{2}$ Growth hormone is administered as subcutaneous injections. Injection sites include the upper arm, thighs, buttocks, and abdomen. Children who are diagnosed with one of the following chronic disorders are prescribed growth hormone treatments: growth hormone deficiency, Turner syndrome, small for gestational age, limited degree of production of pituitary hormones, chronic renal failure, and Silver-Russell syndrome.

In The Netherlands, there are eight different brand names for products containing the same active ingredient, ie, growth hormone. ${ }^{3}$ Concentration $(\mathrm{mg} / \mathrm{mL})$ and injection volume $(\mathrm{mL})$ may slightly differ between the brands, but the most important differences are the medical devices used, ie, the injection pens that go with the brands. Each brand has its own instructions for use, including preparation, storage, injection technique, and service program provided by the company.

Daily subcutaneous injections may be perceived as a burden because they can cause pain and bruising. Needle pen injectors or needle-free delivery systems designed to minimize pain may reduce the discomfort. ${ }^{4}$ The effect of therapy is closely monitored by health care professionals and the dosage may be adjusted every 3-6 months. However, these visits can be stressful for both children and parents because blood tests and x-rays may well be required.

Skipping of injections, ie, nonadherence, is not followed by immediate negative effects. Positive effects, associated with adequate adherence, are to a certain extent difficult for the children and parents to link to treatment because there is a time lag. Influencing behavior, ie, improving adherence, is a challenge, especially if one takes into account that patients are mostly children and adolescents. ${ }^{2}$

Patient perceptions of treatment benefit play a role in patient acceptance of physician recommendations concerning treatment. ${ }^{5}$ The key to better understanding of patient acceptance of growth hormone therapies is to understand parental perceptions and beliefs concerning illness and treatment, because parents are in control of the first years of treatment and often beyond. This entails better understanding of where parents gather their information, what information they are missing, what determines the relevance of particular medication benefits to patients (and their carers), and what benefits are important to patients in comparing which of the relevant medications they will accept.

Few studies have explicitly examined the opinions of parents in the area of growth hormone therapy. In this paper, we take the first step in examining parents' views regarding growth hormone treatment for their child. The overall aim of our study was to gain a better understanding of parents' perceptions and views on self-management of treatment with growth hormone.

\section{Materials and methods}

The Patient Intelligence Panel (PIP) Health is a patient research company. PIP Health developed the questionnaire for the current study in cooperation with the Dutch Society for Growth Hormone Treatment (NVGG), which is a Dutch patient advocacy group for persons who are prescribed or who are taking care of persons prescribed growth hormone. NVGG has some 300 members. PIP Health's patient panel secured the study sample, and programmed and fielded the survey in early 2011. An invitation email was sent via the NVGG database to approximately 300 parents of children using growth hormone. Potential study participants received an email message inviting them to complete an online questionnaire that would take approximately 10 minutes to fill in. The email included a link to the online questionnaire and offered patients a $€ 10$ charitable donation to the NVGG society as an incentive. The invitation clearly stated that the survey was designed regarding patient anonymity and confidentiality. Of the 300 patients invited, 69 completed the questionnaire and 69 were included in the reported analysis.

Parents who had indicated that they had a child who was using growth hormone treatment upon enrolling in the PIP Health patient panel were recruited for participation. The study population for this analysis was 69 adult individuals who had a child aged 1-18 years with physician-diagnosed (reported by parents) growth hormone deficiency $(n=33)$, Turner syndrome $(n=9)$, small for gestational age $(4)$, limited degree of production of pituitary hormones $(n=17)$, chronic renal failure $(n=2)$ or Silver-Russell syndrome $(n=4)$. Most of the parents $(78 \%)$ were members of a patient advocacy group, being the NVGG in most cases.

\section{Sources and quality of information}

In addition to assessing the characteristics of the children and the indication and type of growth hormone device used, the study included measures of device-related information as well as the quality of this information. Parents could choose between the following seven options in the survey regarding the source of information (more than one option could be checked): the doctor, nurses at the hospital, the pharmaceutical company, other parents/patients, patient advocacy groups, the Internet (search engines), and a category entitled "other". 


\section{Involvement in decision-making process}

The questionnaire incorporated questions about whether doctors presented the different growth hormone devices and whether parents felt that they had freedom of choice in choosing a device for their child. The last question had three response scales, consisting of "Yes I was totally free to choose", "The hospital advised me on a device but I was free to choose" and "No I was not free to choose".

\section{Operational aspects and support}

Two questions related to administration of growth hormone treatment by the child itself, and the opinion of parents about whether or not the freedom to choose a device was beneficial for them as parents and for the child. The parents could respond on a four-point scale ("totally agree" to "totally disagree"). Another question related to the added value of having a parent with experience of treating their child with growth hormone available for support alongside one's own doctor and whether they would be open to help other parents.

\section{Emotional problems and support}

Opinions of parents on the role of emotional factors in their child's growth hormone treatment were identified with regard to anxiety about administration of growth hormone, support on addressing anxiety about administration, reluctance to administer, and support on this reluctance when entering adolescence.

Furthermore, parents indicated whether their child was anxious about the daily administration of growth hormone; there were four response options ranging from "very anxious" to "totally not anxious". One question asked to what extent anxiety influenced their day, measured in minutes of anxious thoughts. The answers consisted of four categories. Furthermore, the parents could suggest whether emotional support to conquer the anxiety was welcome; they could choose between "very welcome", "welcome", and "not welcome".

Parents' satisfaction with the emotional support provided by health care professionals for their child's anxiety was assessed on a four-point scale, ranging from "totally satisfied" to "totally not satisfied". Furthermore, parents could indicate whether they saw an increase in reluctance to administer growth hormone when their child entered puberty, and whether they needed support. The same scales were used as for the questions about anxiety, mentioned previously.

\section{Results}

The average age of the children was 9.58 years. In this group of children $(n=69), 73 \%$ had been using growth hormone treatment for more than 3 years, 9\% for approximately 2 years, $12 \%$ for approximately one year, and $6 \%$ for less than one year. Seventy percent $(n=48)$ of the children were using a needle device and $30 \%(n=21)$ were using the needle-free device (ZomaJet Vision). Nine percent $(n=6)$ indicated that they had switched from one growth hormone device to another during the treatment period.

\section{Sources and quality of information}

Parents' queries about the condition and devices are presented in Table 1. The parents had more questions about the medical condition than about the device (197 versus 113). Doctors were the most important source of information at the time of diagnosis for both the condition (94\%) and growth hormone devices (70\%). The Internet and the patient advocacy group played an important role in providing information regarding the condition (used as sources of information by $68 \%$ and $52 \%$ of parents, respectively). Approximately twice as many parents were informed about their child's condition by the Internet or the patient advocacy group than by a nurse $(28 \%)$. However, the nurse played a major role in providing information regarding the devices $(32 \%)$.

\section{Involvement in decision-making process about the device}

At the time of diagnosis and starting growth hormone treatment, $68 \%(n=44)$ of the parents were presented with just one growth hormone device, whereas $32 \%(n=21)$ were shown a minimum of two different types (see Figure 1). Of the latter group, $71 \%(\mathrm{n}=15)$ received a "practice administration" in order to try out one or more of the different devices. In response to whether the parents felt they had freedom in the choice of device, $48 \%$ said that they felt they did not have freedom of choice, $9 \%$ indicated that they felt free to choose to some extent, and $43 \%$ answered that they felt fully free to choose a device.

Table I Sources used by parents for information about the condition and the growth hormone device (more than one option could be checked)

\begin{tabular}{lll}
\hline Information source & $\begin{array}{l}\text { Queries about } \\
\text { condition } \\
(\mathbf{n}=1 \mathbf{1 9 7})\end{array}$ & $\begin{array}{l}\text { Queries about } \\
\text { device } \\
(\mathbf{n}=1 \mathbf{1} \mathbf{3})\end{array}$ \\
\hline Doctor & $94 \%$ & $70 \%$ \\
Internet (search engines) & $68 \%$ & $19 \%$ \\
Patient advocacy group & $52 \%$ & $12 \%$ \\
Practice nurse & $28 \%$ & $32 \%$ \\
Other patients & $25 \%$ & $9 \%$ \\
Pharmaceutical company & $16 \%$ & $19 \%$ \\
\hline
\end{tabular}




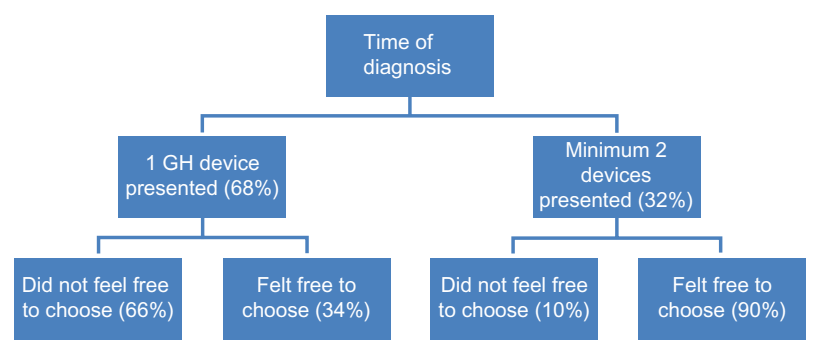

Figure I Number of devices presented in the hospital at the start of the treatment. Abbreviation: $\mathrm{GH}$, growth hormone.

\section{Operational aspects and support}

Among the parents participating in the survey, $92 \%$ believed that self-administration by the child would give them and the child more freedom in their daily lives, and $65 \%$ of the parents also saw the benefit of a specially designed course to enable children/teenagers to learn to administer growth hormone themselves when they were old enough. Most parents $(53 \%)$ believed that at the age of 10 or 11 years their child would be ready for this training. In Table 2 , the age distribution is presented regarding parents' views concerning the right time to train their child in self-administration.

Among the parents, $79 \%$ answered that they would see the added value of having a parent with experience of treating their child with growth hormone available alongside their doctor, whereas $10 \%$ were neutral about this idea, and $11 \%$ did not see it as adding value. Of the parents who would appreciate advice from other parents, $91 \%$ would also be open to supporting other parents themselves.

\section{Emotional problems and support}

Regarding anxiety about the needle or the pain associated with administering the injection, $37 \%$ ( 26 of all the children) felt anxious about the device used, according to their parents. Of these children, parents felt that $12 \%(\mathrm{n}=3)$ were quite afraid and $17 \%(n=4)$ were very afraid of the device, with $71 \%$ being a little bit afraid.

In order to measure the prevalence of anxious thoughts per day for most children, the parents who indicated their child had experienced anxiety were asked to estimate the number of minutes of anxious thoughts their child had regarding growth hormone administration. The majority ( $81 \%)$ estimated that their child suffered from anxiety up to a maximum

Table 2 Age distribution for starting self-administration of growth hormone treatment $(n=4 I)$

\begin{tabular}{ll}
\hline $6-7$ years & $10 \%$ \\
$8-9$ years & $32 \%$ \\
$10-11$ years & $53 \%$ \\
$>12$ years & $5 \%$ \\
\hline
\end{tabular}

of 4 minutes a day, 4\% assessed that it was 5-10 minutes per day, and 11\% estimated 11-30 minutes a day. Four out of the five parents who considered that the child had more than 4 minutes of anxious thought indicated that their child was "afraid" or "very afraid" of their treatment.

Of the 26 parents who mentioned that their child was anxious about growth hormone administration, $69 \%(\mathrm{n}=18)$ were using a needle device and $31 \%(n=8)$ were using the needle-free device. Of these parents, $83 \%$ would appreciate reimbursed support to counter the anxiety, even though $75 \%$ of these parents were satisfied with the guidance of a health care professional to tackle the anxiety of their child. Of the seven parents with children who were anxious or very anxious, more than half were not satisfied with the support from the nurse or psychologist. Table 3 shows quotes from nine parents describing how they dealt with the anxiety of their child.

Twenty parents with children in the age range $11-18$ years were asked whether they had seen an increase in reluctance to receive growth hormone treatment after the child entered puberty. Forty percent of parents agreed with this statement and $57 \%$ did welcome the opportunity for a psychologist to give support to them and their children to deal with emotional problems resulting from growth hormone treatment.

\section{Discussion}

Few studies have explicitly examined the opinions of parents in the growth hormone therapy area. Therefore, we examined parents' views of their child's growth hormone treatment. The overall aim of our study was to gain a better understanding of perceptions parents have with regard to their child's growth hormone treatment.

Our main results can be summarized as follows. The main source of information was the doctor prescribing the growth hormone treatment. The Internet proved to be another source used by parents to gain knowledge about the condition and the devices used for administration of growth hormone. The nurse played an important role in providing information about the device to parents. Parents did not feel that they were involved in the process of making treatment decisions. Half of all the respondents indicated that they did not have any freedom of choice between the devices. More than two-thirds of the parents were only presented with one device to administer growth hormone to their children, which supports the conclusion of lack of involvement of parents in the treatment choice.

Parents were willing to help other parents and saw this as adding value to the growth hormone treatment procedure. Administration of growth hormone can create anxiety for the child which can last for many years. Support to conquer the 
Table 3 Parents' comments and opinions

\begin{tabular}{|c|c|c|c|c|}
\hline Respondent & Comment & Anxiety level & $\begin{array}{l}\text { Growth hormone } \\
\text { treatment }\end{array}$ & $\begin{array}{l}\text { Age } \\
\text { (years) }\end{array}$ \\
\hline $\mathrm{I}$ & $\begin{array}{l}\text { It works best to just inject, otherwise they will be longer } \\
\text { in a stressful feeling. Watch your child what he/she finds } \\
\text { most comfortable. Let him help if they need it. }\end{array}$ & Quite afraid & Zomajet ${ }^{\circledR}$ & 3 \\
\hline 2 & $\begin{array}{l}\text { Go to the child psychologist. We are in the middle of the } \\
\text { process and it goes slowly, but we are moving forward. } \\
\text { Support from the health care professionals is moderate, } \\
\text { but it might be due to the fact that we found support in the } \\
\text { area we live in. }\end{array}$ & $\begin{array}{l}\text { Very much } \\
\text { afraid }\end{array}$ & Nutropin ${ }^{\circledR}$ & 5 \\
\hline 3 & $\begin{array}{l}\text { Bedtime is already a difficult time anyway! It is difficult } \\
\text { to think that my child goes to sleep with these anxious } \\
\text { thoughts. A suggestion could be to get a DVD for a better } \\
\text { and longer explanation. A cartoon might be an idea? } \\
\text { My son was afraid for years on end. Methods to distract him } \\
\text { did not work, you simply cannot explain to a child of 5-6 years old } \\
\text { why he needs to do this, I saw so many tears. }\end{array}$ & Quite afraid & Norditropin ${ }^{\circledast}$ & 12 \\
\hline 4 & $\begin{array}{l}\text { Do not show your own discomfort, this will make } \\
\text { it worse for the child. We are counting before the shot, } \\
\text { and counting during the injection. }\end{array}$ & $\begin{array}{l}\text { Very much } \\
\text { afraid }\end{array}$ & Nutropin & 6 \\
\hline 5 & $\begin{array}{l}\text { I'm desperate and can do with some suggestions. } \\
\text { The doctor and the nurse who comes to our home do not } \\
\text { take the anxiety as a serious problem. }\end{array}$ & Quite afraid & Norditropin & 5 \\
\hline 6 & $\begin{array}{l}\text { We have a good experience with a hypnotherapist. We had a } \\
\text { struggle every night but after two sessions with the therapist our } \\
\text { daughter started to administer the growth hormone herself! } \\
\text { The nurses told me that as long as my child sleeps at night } \\
\text { and thus doesn't worry about it, no actions should be undertaken. } \\
\text { In the mean time, we struggle every night with the administration } \\
\text { of the growth hormone to a terrified crying child. }\end{array}$ & $\begin{array}{l}\text { Very much } \\
\text { afraid }\end{array}$ & Norditropin & 7 \\
\hline 7 & $\begin{array}{l}\text { Do not make a drama of the injection, stick with a } \\
\text { positive approach only. }\end{array}$ & Quite afraid & Zomajet & 13 \\
\hline 8 & $\begin{array}{l}\text { We found out by coincidence that there is a needle-free } \\
\text { device. Now that we use that he doesn't have the anxiety } \\
\text { anymore. But this should be explained and I think everyone } \\
\text { should have that choice. }\end{array}$ & Little bit afraid & Zomajet & 7 \\
\hline 10 & $\begin{array}{l}\text { They told us to distract her. At the point of the injection } \\
\text { she definitely does not let us distract her! }\end{array}$ & Little bit afraid & Norditropin & 9 \\
\hline
\end{tabular}

fears of the children was welcomed by the Dutch parents. For the parents with adolescent children, professional support to guide their children through emotional shifts in behavior towards growth hormone treatment was also welcomed.

\section{Our study results in the context of related research}

These results provide insights about the Dutch population confronted with daily administration of growth hormone to their children. Despite the clear benefits of replacement therapy with growth hormone for most subjects, poor adherence to the treatment regimen is common. ${ }^{5}$ Despite the difficulties in assessing behavior and outcomes, increasing evidence suggests that poor adherence is quite common among patients (children and adults) taking growth hormone, with adherence estimated between $36 \%$ and $49 \%$ during the interval since the last clinic visit. ${ }^{5}$

From data on filled prescriptions, Hunter et al found that $33 \%$ of their patients received less than $80 \%$ of their expected growth hormone dose. Similarly, Desrosiers et al reported that $15 \%-24 \%$ of 630 children missed more than three injections per month. ${ }^{6,7}$

In a study in the UK of 75 children using growth hormone, $23 \%$ missed more than two injections a week. In this study, lower adherence was associated with reduced height velocity and a free choice of injection device was associated with better adherence. In the subgroup of children who missed more than two injections a week, 23\% were given a choice of growth hormone devices, whereas in the subgroup of children who never missed an injection, $81 \%$ were given a choice. ${ }^{8}$ 
As this research shows, parents see their doctor as the main source of information. When it comes to information about the device, they turn to the nurse who, generally speaking, has more time for the parents and children. This could add to adherence because parents often do not feel fully involved in treatment decisions, as shown in this study. Involvement in decision-making is another aspect that aids acceptance by parents and thus children using growth hormone. ${ }^{9}$ Also, the Internet should be a valuable resource for parents to find information about their child's condition. The information provided should be accurate and easy for the parents (and adolescent children) to comprehend. ${ }^{10}$ It is suggested that organizations in the health care environment should invite patient feedback in order to check whether their information is accurate and relevant for the end-user of this information. ${ }^{11}$

This study confirms that parents perceive that selfadministration of growth hormone can aid treatment; the most commonly suggested age range for the child to start administering growth hormone was 10-11 years. In another study of 73 children with an average age of 10 years using a needle-free ZomaJet Vision system, about one-third of the children were injecting themselves without having received any training by health care professionals.

\section{Limitations}

Given the state of the art of research on this topic, our study is an explanatory one aiming at gaining insight into parents' points of view regarding growth hormone therapy. The study sample was selected because it represents members of a patient advocacy group.

Another limitation is the fact that there is no report of the time periods over which people were being asked to recall information. For example, parents of a child who is 18 years old now may have been offered a choice of device 14 years previously and there is evidence that people have difficulties remembering medical advice, choices, and support, especially at the time of the diagnosis. Without information about the exact length of use of devices (and diagnosis), statements about switch behavior and behavior in searching for information is difficult to assess.

\section{Research implications}

It might be useful to increase our understanding of patients' beliefs and their determinants by acquiring prospective information on beliefs but also clinical information and prescription data, especially in new users of medication. ${ }^{12}$

Future research should include parents who are not members of such a group because patient advocacy tends to be associated with higher levels of knowledge and involvement in clinical matters. In addition, future research should assess explicitly parents' perceptions regarding the illness and treatment. Children themselves should be an additional source of information on these two topics.

There is already evidence of the relationship between adherence and growth response. ${ }^{13}$ Further studies are needed to quantify improvement in adherence and the relationship between adherence and improvement in growth outcomes, and of involving parents and children more in the choice of growth hormone device with an aim to optimize adherence to growth hormone. Illness perceptions and treatment beliefs in the context of the extended common sense model described by Horne and Weinman ${ }^{14}$ should be used to add strength to the research. Interventional studies are called for in studying methods to reduce anxiety, involve patients in less anxiety-provoking methods of delivering growth hormone, and in improving quality of life in children and their parents. These studies should take into account the time periods of the children's growth hormone treatment and correlate these with their need for information and their behavior of searching for this information.

\section{Clinical implications}

Understanding parents and their views on growth hormone treatment may help health care providers to develop targeted interventions to improve medication adherence. Acceptance through freedom of choice in growth hormone device could be an effective first step that a health care professional could take by showing all devices available to the children. Another useful addition could be an information sheet/website where all information is presented to the parents about the condition and the devices available. As nurses continue to work with patients more closely to improve medication use and outcomes, it might be useful for nurses to hand out this information sheet or website to parents even before the start of treatment. Self-administration training courses could be presented to the child when he/she gets older. Emotional problems, such as resistance during puberty and needle anxiety, could be reduced by providing professional psychological support to the children. Health care professionals should take these emotional problems more seriously in order for further improvements in delivering medication without high stress levels in patients and their caregivers, resulting in a positive effect on adherence with growth hormone treatment in children.

\section{Acknowledgments}

The authors wish to acknowledge the Dutch patient organization NVGG and the patient platform PIP Health, for their 
members who participated in the survey, and Scott Mason, social research student, London Metropolitan University, for his time and effort in contributing to literature review, advice, and data analysis.

\section{Disclosure}

This work was supported by an unrestricted grant from Ferring BV, The Netherlands. NvD has received a consulting fee and research funding from Ferring BV, The Netherlands.

\section{References}

1. Growth Hormone Deficiency. UK Child Growth Foundation. Available from: http://www.childgrowthfoundation.org/ghd.htm. Accessed April 12, 2012.

2. Kind en Groei, kenniscentrum voor groei en ontwikkeling van het kind. Child and Growth, knowledge center for growth and the development of the child. Jaarverslag, Rotterdam, 2009. Available from: http://www. kindengroei.nl/site/index.php. Accessed April 12, 2012.

3. Royal Dutch Pharmaceutical Company. KNMP tax. Available from: http://www.knmp.nl/. Accessed April 12, 2012.

4. Rubin RR, Peyrot M. Factors affecting use of insulin pens by patients with type 2 diabetes. Diabetes Care. 2008;31:430-432.

5. Haverkamp F, Gasteyger C. A review of biopsychosocial strategies to prevent and overcome early-recognized poor adherence in growth hormone therapy of children. J Med Econ. 2011;14:448-457.
6. Hunter I, de Vries C, Morris A, et al. Human growth hormone therapy: poor adherence equals poor growth. Arch Dis Child. 2000;82 Suppl $1: 28$.

7. Desrosiers P, O'Brien F, Blethen S. Patient outcomes in the GHMonitor: the effect of delivery device on compliance and growth. Pediatr Endocrinol Rev. 2005;2:327-331.

8. Kapoor RR, Burke SA, Sparrow SE, et al. Monitoring of concordance in growth hormone therapy. Arch Dis Child. 2008;93:147-148.

9. Smith H, Gooding S, Brown R, Frew A. Evaluation of readability and accuracy of information leaflets in general practice for patients with asthma. Br Med J. 1998;317:264-265.

10. van Dongen N. Let's be effective, let the patients talk! Does 'patient intelligence' have an effect on improvements in quality within the healthcare environment? Patient Intelligence Journal. 2009;1:1-5.

11. Oyarazabal M, Aliaga M, Chueca M, et al. Multicentre survey on compliance with growth hormone therapy: what can be improved? Acta Pediatr. 1998;87:387-391.

12. Kaptein AA, Klok T, Moss-Morris R, Brand PLP. Illness perceptions: impact on self-management and control in asthma. Curr Opin Allergy Clin Immunol. 2010;10:194-199.

13. Cutfield WS, Derraik JG, Gunn AJ, et al. Non-compliance with growth hormone treatment in children is common and impairs linear growth. PLoS One. 2011;6:e16223.

14. Horne R, Weinman J. Self-regulation and self-management in asthma: exploring the role of illness perceptions and treatment beliefs in explaining non-adherence to preventer medication. Psychol Health. 2002;17:17-32.
Patient Preference and Adherence

\section{Publish your work in this journal}

Patient Preference and Adherence is an international, peer-reviewed, open access journal focusing on the growing importance of patient preference and adherence throughout the therapeutic continuum. Patient satisfaction, acceptability, quality of life, compliance, persistence and their role in developing new therapeutic modalities and compounds to

\section{Dovepress}

optimize clinical outcomes for existing disease states are major areas of interest. This journal has been accepted for indexing on PubMed Central. The manuscript management system is completely online and includes a very quick and fair peer-review system. Visit http://www.dovepress.com/ testimonials.php to read real quotes from published authors. 